\title{
Medical Nutrition Therapy for Type-2 Diabetes
}

\author{
Gulfam Ahmad Cheema* \\ Zulifiqar Haider Medical Complex, Pakistan
}

Submission: October 20, 2019; Published: December 17, 2019

*Corresponding author: Gulfam Ahmad Cheema, Zulifiqar Haider Medical Complex, Pakistan

\section{Abstract}

Medical nutrition therapy remains the cornerstone in chronic disease management, apart from medication and regular physical activity. Various clinical practice guidelines and position papers from worldwide associations have incorporated specific nutrition recommendations in managing chronic diseases such as diabetes mellitus, hypertension, hyperlipidaemia, gout and chronic renal failure, which aim to prevent further complications or other co-morbidities arise from these chronic medical conditions. In addition, specific issues such as carbohydrate exchange, glycaemic index and glycaemic load for people with diabetes; DASH diet for hypertensive individuals, latest concerns on trans-fat, the usage of plant sterol and soluble fibre in enhancing lipid lowering will also be addressed in this article.

Biography: Gulfam Ahmad Cheema has completed his M.B.B.S at the age of 24 years from King Edward Medical College Lahore and PostGraduation in Medicine (F.C.P.S) from college of Physician and Surgeons of Pakistan in February 2011. He has research work in medical nutrition therapy for diabetes and now working as Consultant Physician in Zulifiqar Haider Medical Complex, Gujrat, Pakistan (Established in 1962).

Keywords: Mortality; Morbidity; Diet; Physical Activity; Health; Chronic diseases; Type-2 diabetes; Nutrition therapy; Diabetes; Hyperlipidaemia

\section{Introduction}

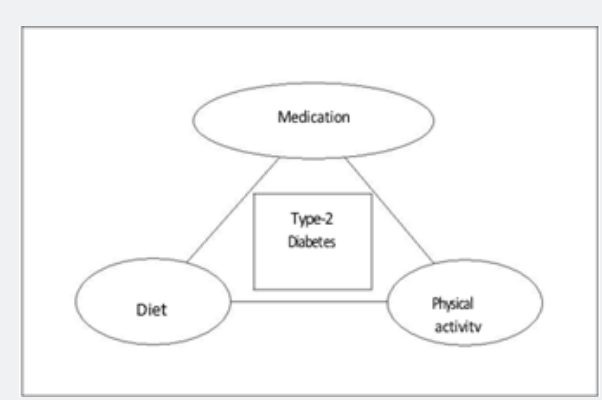

Figure 1: Components of type-2 diabetes management.

The rapidly increasing worldwide prevalence of Type2 diabetes, hypertension and hyperlipidaemia as a result of population's progress to adopt an unhealthy eating pattern and sedentary lifestyle has led to a significant proportion of mortality and morbidity. In view of this rising burden of Type2 diabetes, the Global Strategy for Diet, Physical Activity and Health was established by WHO in the year 2004 [1] to promote primary prevention of chronic diseases via population-based approach. Hence, dietary component remains the cornerstone in chronic disease management for people who suffer from chronic diseases as well as for those who are at risk of developing diseases, apart from medication and physical activity as shown in Figure 1.

In terms of dietary component, various worldwide associations such as American Diabetes Association, American Heart Association, American Dietetics Association, British Dietetics Association, National Cholesterol Education Programme (NCEP) Adult Treatment Panel III, Dietitians Association of Australia and New Zealand Dietetics Association have acknowledged the importance of medical nutrition therapy as an integral part in chronic disease management and hence they have incorporated the principles and specific nutrition recommendations of medical nutrition therapy for specific chronic disease as part of the evidence- based clinical practice guidelines.

The term "medical nutrition therapy" was introduced by American Dietetics Association [2] in 1994 to better articulate the nutrition therapy process. It is defined as the use of specific nutrition services to treat an illness, injury or a disease which involves two phases: (i) assessment of the nutritional status of the client; and (ii) treatment, which includes nutrition therapy, counseling and the use of specialized nutrition supplements. Furthermore, the position of American Dietetics Association 


\section{Current Research in Diabetes \& Obesity Journal}

states that medical nutrition therapy is effective in treating disease and preventing disease complications, resulting in health benefits and cost savings for the public. Therefore, medical nutrition therapy provided by dietetics professionals is an essential reimbursable component of comprehensive health care services [3].

In short, medical nutrition therapy refers to the dietary management of patients with diet-related medical conditions in the form of assessment, education and counseling and recommendation of special nutrition supplements, in order to improve the patient's overall health status and to reduce healthcare cost involved in disease management. In terms of cost effectiveness of medical nutrition therapy in United States, it is estimated that by incorporating medical nutrition therapy component provided by a registered dietitian in management of patients with hyperlipidaemia could save cost of $\$ 1,300$ per patient per year and to help a patient with stage 1 hypertension decrease the dosage of medication for an estimated 5-year cost Savings of more than $\$ 9,003$. In this article, principles of medical nutrition therapy, nutrition recommendations and other relevant diet-related issues such as practical food tips, food myths as well as learning points for diabetes mellitus, lipid disorders will be highlighted and addressed respectively.

\section{Diabetes Mellitus}

\section{Medical nutrition therapy guidelines}

The overall prevalence of diabetes mellitus accounts for about 8.2\% of Pakistan population aged 18-69 years according to the National Health Survey (NHS) 2010 of Ministry of Health (MOH). In 2004, diabetes was the 5th leading cause of death in Pakistan with $3.0 \%$. of all deaths being attributable to diabetes alone [4].

Type 2 diabetes is the more common form of diabetes, mainly occurring in elder persons and is associated with obesity among the population. In view of this, according to the clinical practice guidelines (CPG) for diabetes mellitus published by MOH in 2010 [5], medical nutrition therapy should emphasize on gradual weight loss $(0.25$ to $1.0 \mathrm{~kg} /$ week) for overweight people with type 2 diabetes via diet and lifestyle modifications; whereas for type 1 diabetes, the main effort should be directed towards dietary manipulation and insulin therapy to improve glycaemic control. Also, diet plan should be tailored to individual preference, physical activity level, cultural and ethnic practices; and dietary habits. Special attention on dietary requirements should be paid to patients with diabetes during their sick days, travel, exercise; pregnancy and lactation for female patients as well as youth and elderly persons.

Table 1: Medical nutrition therapy guidelines for people with diabetes.

\begin{tabular}{|c|c|}
\hline Nutrients & Daily Recommended Intake \\
\hline Total carbohydrates & $50 \%$ to $60 \%$ of total calories \\
\hline Total protein & $15 \%$ to $20 \%$ of total calories \\
\hline Total fat & $<30 \%$ of total calories \\
\hline Saturated fat & $<300 \mathrm{mg} /$ day \\
\hline$<10 \%$ of total calories & $20-35 \mathrm{~g} /$ day \\
\hline Total cholesterol & $<2,000 \mathrm{mg} /$ day \\
\hline Total dietary fibre & People with poorly controlled diabetes or overweight should abstain \\
\hline Total sodium intake & from alcohol
\end{tabular}

Table 1 is a summary of medical nutrition therapy guidelines for people with diabetes of each specific nutrients and respective

Table 2: Goals of nutrition therapy.

\begin{tabular}{|c|c|}
\hline Levels of Prevention & Goals of Medical Nutrition Therapy \\
\hline Primary & $\begin{array}{c}\text { To prevent diabetes in those who are obese and pre-diabetes via healthy eating and regular exercise to achieve } \\
\text { moderate weight loss. }\end{array}$ \\
\hline Secondary & $\begin{array}{l}\text { To prevent complications, arise from diabetes for those who suffer from diabetes by achieving optimal } \\
\text { glycaemic, blood pressure and lipid control. }\end{array}$ \\
\hline Tertiary & To prevent morbidity and mortality by slowing down the progression rate of complications arise from diabetes. \\
\hline
\end{tabular}

The nutrition recommendations and interventions for people with diabetes as published in the position statement of American Diabetes Association (ADA), Diabetes Care, January 2008 [6] aim at all levels of diabetes prevention - primary, secondary and tertiary as shown in Table 2. It has been shown recommended daily intake according to $\mathrm{CPG}$ for diabetes mellitus 2010, MOH. by clinical trials that medical nutrition therapy decreases HbA1c (Glycosylated haemoglobin) by $\sim 2.0 \%$ with the usage of Cinamin especially in type- 2 diabetes. In type 2 diabetes. Metaanalysis of studies also report that medical nutrition therapy reduces LDL cholesterol level by $1525 \mathrm{mg} / \mathrm{dl}$ as well as support 


\section{Current Research in Diabetes \& Obesity Journal}

a role in lifestyle modification in managing hypertension. Hence, individuals who have pre- diabetes or diabetes should receive individualised medical nutrition therapy; and such therapy is best provided by a Doctor who is familiar with the components of diabetes medical nutrition therapy. (B)

Table 3: Medical nutrition therapy in ADA position statement.

\begin{tabular}{|c|c|}
\hline Components & Nutrition recommendations and interventions \\
\hline \multirow{6}{*}{$\begin{array}{c}\text { Energy } \\
\text { balance, over- } \\
\text { weight and } \\
\text { obesity }\end{array}$} & $\begin{array}{l}\text { In overweight and obese insulin-resistant individuals, modest weight loss has been shown to improve insulin resistance. Thus, overweight and obesi- } \\
\text { ty loss is recommended for all such individuals who have or are at risk of having diabetes. (A) }\end{array}$ \\
\hline & For weight loss, either low carbohydrate or low-fat calorie restricted diet may be effective in the short term (up to 1 year). (A) \\
\hline & $\begin{array}{c}\text { For patients on low carbohydrate diets, monitor lipid profiles, renal function and protein intake (in those with nephropathy), and adjust } \\
\text { hypoglycemic therapy as needed. (E) }\end{array}$ \\
\hline & $\begin{array}{l}\text { Physical activity and behavior modification are important components of weight loss programmes and are most helpful in maintenance of } \\
\text { weight loss. (B) }\end{array}$ \\
\hline & $\begin{array}{l}\text { Weight loss modifications may be considered in the treatment of overweight and obese individuals with type } 2 \text { diabetes and can help achieve } \\
\qquad \text { a 5-10\% weight loss when combined lifestyle modifications. }\end{array}$ \\
\hline & $\begin{array}{c}\text { Bariatric surgery may be considered for some individuals with type } 2 \text { diabetes and Body Mass Index (BMI) }>35 \mathrm{~kg} / \mathrm{m}^{2} \text { and can result in } \\
\text { marked improvements in glycaemia. The long-term benefits and risks of bariatric surgery in individuals with pre- diabetes or diabetes contin- } \\
\text { ue to be studied. (B) }\end{array}$ \\
\hline \multirow[t]{6}{*}{$\begin{array}{l}\text { Preventing dia- } \\
\text { betes (primary } \\
\text { prevention) }\end{array}$} & $\begin{array}{l}\text { Among individuals at high risk for developing type } 2 \text { diabetes, structured programmes that emphasize lifestyle changes that include reduced } \\
\text { calories and reduced intake of dietary fat, can reduce the risk for developing diabetes and are therefore recommended (A) }\end{array}$ \\
\hline & $\begin{array}{l}\text { Individuals at high risk for type } 2 \text { diabetes should be encouraged to achieve the USDA recommendation for dietary fibre (14g fibre/ } \\
\qquad 1,000 \mathrm{kcal} \text { ) and foods containing whole grains (one half of grain intake). (B) }\end{array}$ \\
\hline & $\begin{array}{l}\text { There is not sufficient, consistent information to conclude that low-glycaemic load diets reduce the risk for diabetes. Nevertheless, low-glycae- } \\
\text { mic index foods that are rich in fibre and other important nutrients are to be encouraged. (E) }\end{array}$ \\
\hline & $\begin{array}{l}\text { Observational studies report that moderate alcohol intake may reduce the risk for diabetes, but the data do not support recommending alco- } \\
\text { hol consumption to individuals at risk of diabetes. (B) }\end{array}$ \\
\hline & No nutrition recommendation can be made for preventing type 1 diabetes. (E) \\
\hline & $\begin{array}{l}\text { Although there are insufficient data at present to warrant any specific recommendations for prevention of type } 2 \text { diabetes in youth, it is reasonable to } \\
\text { apply approaches demonstrated to be effective in adults, as long as nutritional needs for normal growth and development are maintained. (E) }\end{array}$ \\
\hline \multirow{12}{*}{$\begin{array}{l}\text { Carbohydrate } \\
\text { in diabetes } \\
\text { management }\end{array}$} & A dietary pattern that includes carbohydrate from fruits, vegetables, whole grains, legumes, and low-fat milk is encouraged for good health. (B) \\
\hline & $\begin{array}{c}\text { Monitoring carbohydrate, whether by carbohydrate counting, exchanges, or experienced-based estimation, remains a key strategy in achiev- } \\
\text { ing glycaemic control. (A) }\end{array}$ \\
\hline & $\begin{array}{l}\text { The use of glycaemic index and load may provide a modest additional benefit over that observed when total carbohydrate is considered alone. } \\
\text { (B) }\end{array}$ \\
\hline & $\begin{array}{l}\text { Sucrose-containing foods can be substituted for other carbohydrates in the meal plan or, if added to the meal plan, covered with insulin or } \\
\text { other glucose-lowering medications. Care should be taken to avoid excess energy intake. (A) }\end{array}$ \\
\hline & $\begin{array}{l}\text { As for the general population, people with diabetes are encouraged to consume a variety of fibre-containing foods. However, evidence is lack- } \\
\text { ing to recommend a higher fibre intake for people with diabetes than for the population as a whole. (B) }\end{array}$ \\
\hline & Sugar alcohols and non-nutritive sweeteners are safe when consumed within daily intake levels as established by the FDA. (A) \\
\hline & Fat and cholesterol in \\
\hline & $\begin{array}{c}\text { Among individuals at high risk for developing type } 2 \text { diabetes, structured programmes that emphasize lifestyle changes that include moderate } \\
\text { weight loss ( } 7 \% \text { body weight) and regular physical activity (150minutes/week), with dietary strategies including reduced calories and re- } \\
\text { duced intake of dietary fat, can reduce the risk for developing diabetes and are therefore recommended (A) }\end{array}$ \\
\hline & $\begin{array}{l}\text { Individuals at high risk for type } 2 \text { diabetes should be encouraged to achieve the USDA recommendation for dietary fibre (14g fibre/ } \\
\qquad 1,000 \mathrm{kcal} \text { ) and foods containing whole grains (one half of grain intake). (B) }\end{array}$ \\
\hline & $\begin{array}{l}\text { There is not sufficient, consistent information to conclude that low-glycaemic load diets reduce the risk for diabetes. Nevertheless, low-glycae- } \\
\text { mic index foods that are rich in fibre and other important nutrients are to be encouraged. (E) }\end{array}$ \\
\hline & $\begin{array}{l}\text { Observational studies report that moderate alcohol intake may reduce the risk for diabetes, but the data do not support recommending alco- } \\
\text { hol consumption to individuals at risk of diabetes. (B) }\end{array}$ \\
\hline & ecommendation can be made for preventing type 1 diabetes. (E) \\
\hline
\end{tabular}




\section{Current Research in Diabetes \& Obesity Journal}

Although there are insufficient data at present to warrant any specific recommendations for prevention of type 2 diabetes in youth, it is reasonable to apply approaches demonstrated to be effective in adults, as long as nutritional needs for normal growth and development are maintained. (E)

Limit saturated fat to $<7 \%$ of total calories. (A)

Intake of trans fats should be minimized. (E)

In individuals with diabetes, lower dietary cholesterol to $<200 \mathrm{mg} /$ day. (E)

Two or more servings of fish per week (with the exception of commercially fried fish fillets) provide $n-3$ polyunsaturated fatty acids and are recommended. (B)

Protein in diabetes management

For individuals with diabetes and normal renal function, there is sufficient evidence to suggest that usual protein intake (15-20\% of energy) should be modified. (E)

In individuals with type 2 diabetes, ingested protein can increase insulin response without increasing plasma glucose concentrations. Therefore, protein should not be used to treat acute or prevent nighttime hypoglycaemia. (A)

High protein diets are not recommended as a method for weight loss at this time. The long-term effects of protein intake $>20 \%$ of calories on diabetes management and its complications are unknown. Although such diets may produce short-term weight loss and improved glycemia, it has not been established that these benefits are maintained long term, and long-term effects on kidney function for persons with diabetes are unknown. (E)

Alcohol in diabetes management

If adults with diabetes choose to use alcohol, daily intake should be limited to a moderate amount (one drink per day or less for women and two drinks per day or less for men). (E)

To reduce risk of nocturnal hypoglycaemia in individuals using insulin or insulin secretagogues, alcohol should be consumed with food. (E)

In individuals with diabetes, moderate alcohol consumption (when ingested alone) has no acute effect on glucose and insulin concentrations but carbohydrate co-ingested with alcohol (as in a mixed drink) may raise blood glucose. (B)

Micronutrients in diabetes management

There is no clear evidence of benefit from vitamin or mineral supplementation in people with diabetes (compared with the general population) who do not have underlying deficiencies. (A)

Routine supplementation with antioxidants, such as vitamin $\mathrm{E}$ and $\mathrm{C}$ and carotene is not advised because of lack of evidence of efficacy and concern related to long term safety. (A)

Benefit from chromium supplementation in individuals with diabetes or obesity has not been clearly demonstrated and therefore cannot be recommended. (E)

Nutrition intervention for type 1 diabetes

For individuals with type 1 diabetes, insulin therapy should be integrated into an individual's dietary and physical activity pattern. $€$

Individuals using rapid-acting insulin by injection or an insulin pump should adjust the meal and snack insulin doses based on the carbohydrate content of the meals and snacks. (A)

For individuals using fixed daily insulin doses, carbohydrate intake on a day-to-day basis should be kept consistent with respect to time and amount. (C)

For planned exercise, insulin doses can be adjusted. For unplanned exercise, extra carbohydrate may be needed. (E) Nutrition interventions for type 2 diabetes

Individuals with type 2 diabetes are encouraged to implement lifestyle modifications that reduce intakes of energy, saturated and trans fatty acids $=$, cholesterol, and sodium and to increase physical activity in an effort to improve glycaemia, dyslipidaemia, and blood pressure. (E)

Plasma glucose monitoring can be used to determine whether adjustments in foods and meals will be sufficient to achieve blood glucose goals or if medications need to be combine with medical nutrition therapy. (E)

Nutrition interventions for pregnancy and lactation with diabetes

Adequate energy intake that provides appropriate weight gain is recommended during pregnancy. Weight loss is not recommended; however, for overweight and obese women with gestational diabetes (GDM), modest energy and carbohydrate restriction may be appropriate. (E)

Ketonemia from ketoacidosis or starvation ketosis should be avoided. (C)

Medical nutrition therapy for GDM focuses on food choices for appropriate weight gain, normoglycemia and absence of ketones. (E)

Because GDM is a risk factor for subsequent type 2 diabetes, after delivery, lifestyle modifications aimed at reducing weight and increasing physical activity are recommended. (A)

Nutrition interventions for older adults with diabetes

Obese older adults with diabetes may benefit from modest energy restriction and an increase in physical activity; energy requirement may be less than for a younger individual of similar weight. (E)

A daily multivitamin supplement may be appropriate, especially for those older adults with reduced energy intake. (C) 


\section{Current Research in Diabetes \& Obesity Journal}

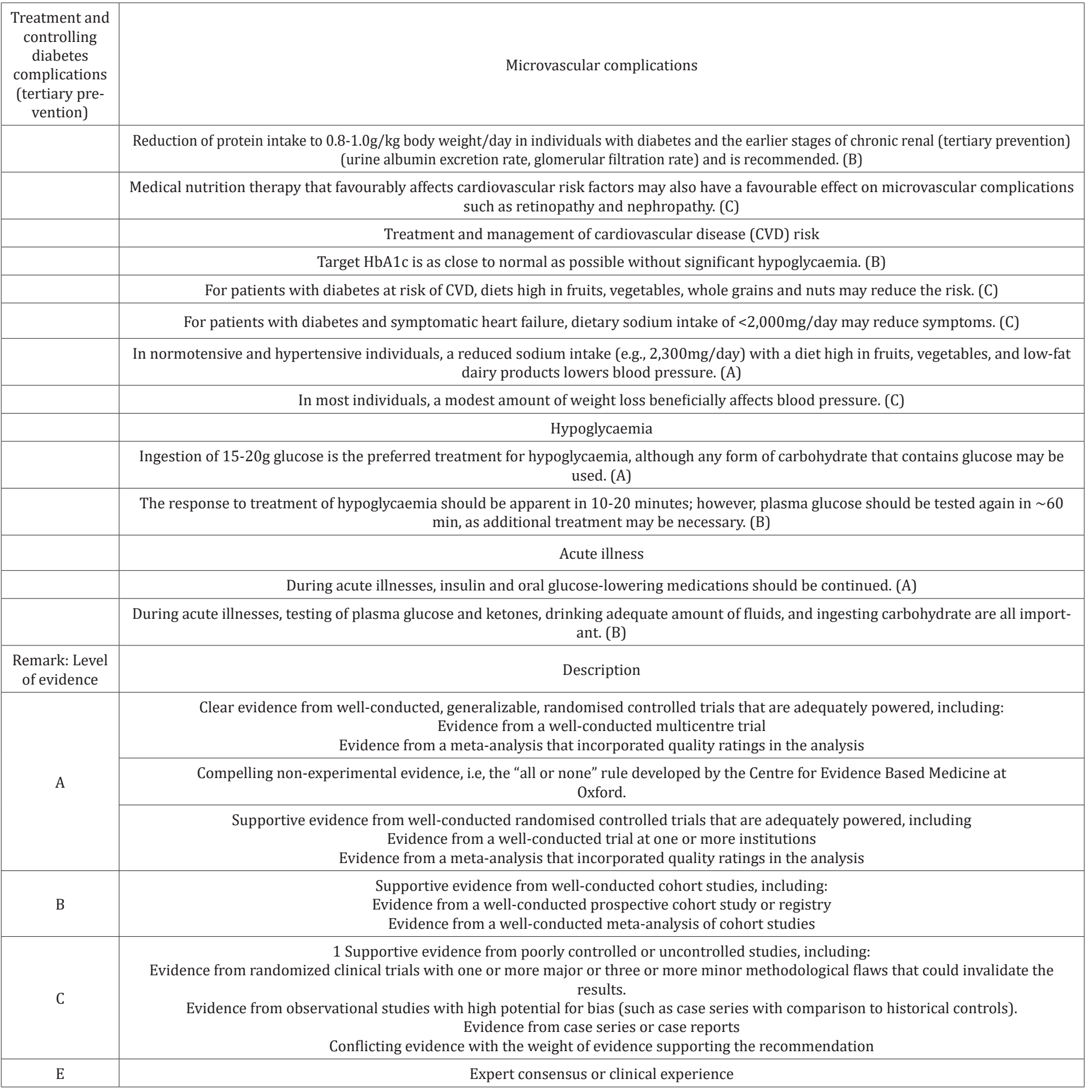

A summary of major nutrition recommendations and interventions of medical nutrition therapy as stated in ADA position statement [7] is shown in Table 3.

\section{Carbohydrate counting and carbohydrate exchange}

As stated in ADA position statement with Grade A evidence - "Monitoring carbohydrate, whether by carbohydrate counting, exchanges, or experienced-based estimation, remains a key strategy in achieving glycaemic control." Hence, carbohydrate counting is a useful way for patients with diabetes who are on insulin treatment to match their carbohydrate amount intake to the rapid insulin dosage. People with diabetes are required to learn how to read the food products labelling and count their total amount of carbohydrate intake from each meal based on their daily allowance of total carbohydrate Table 4. 


\section{Current Research in Diabetes \& Obesity Journal}

Table 4: One Carbohydrate exchange.

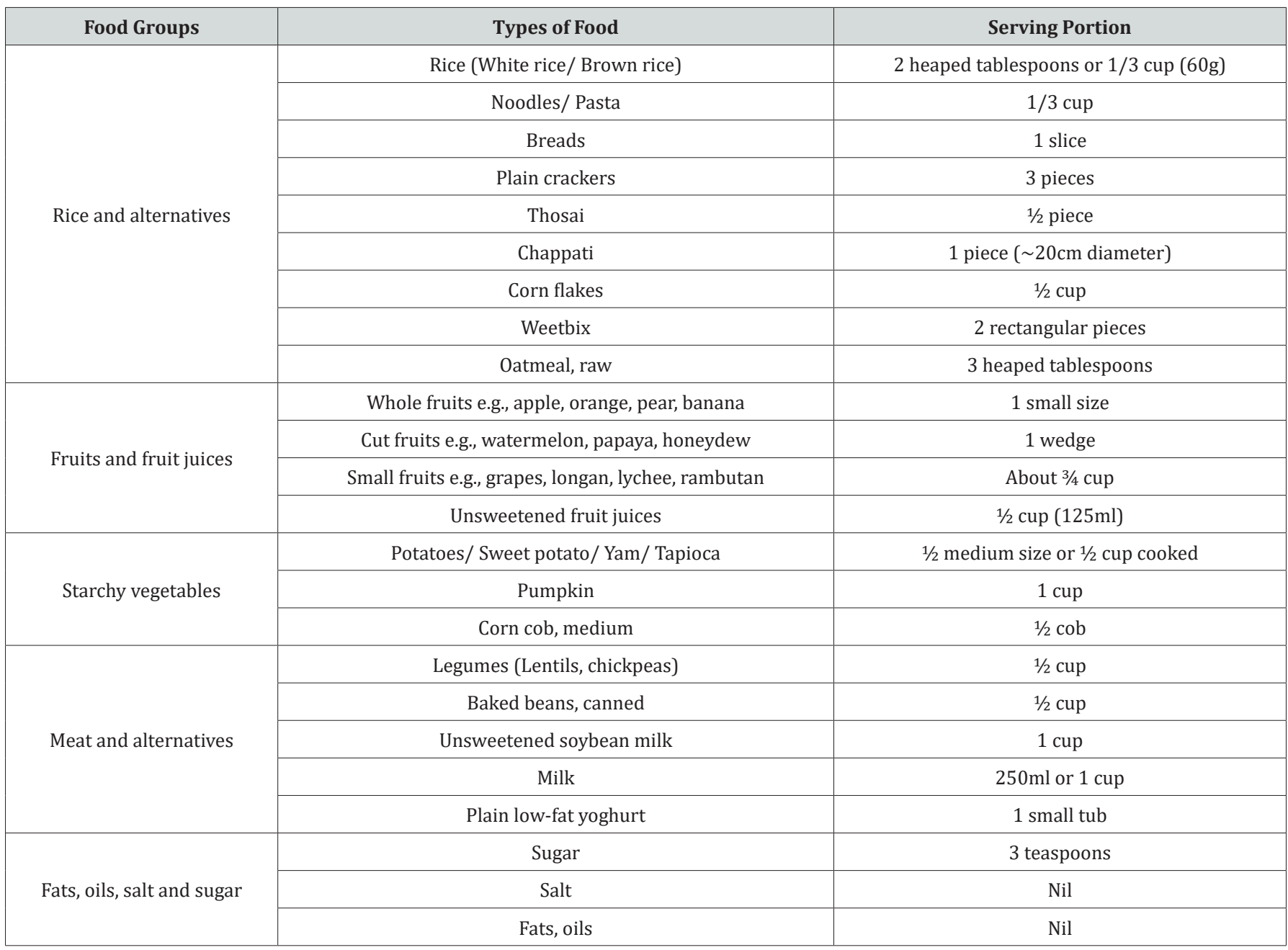

Source: Carbohydrate Exchange List www.diabeteskidsandteens.com.au/pdf/Pump_exchange_list.pdf

Carbohydrate exchange system is an alternative way of carbohydrate counting which offers flexibility and variety of food choices for people with diabetes to adjust their insulin dosage especially for those who are on insulin pump. The standard one carbohydrate exchange is equivalent to 15 grams of carbohydrate.

One Carbohydrate Exchange $=15$ grams Carbohydrate

Table 5: Carbohydrate exchange in hawker foods.

\begin{tabular}{|c|c|c|c|}
\hline Food Item & Serving Size & Per Serving Energy (kcal) & Estimated CHO exchange \\
\hline Fried meehoon, plain & 1 plate & 250 & 5.5 \\
\hline Fried vegetarian meehoon, plain & 1 plate & 549 & 2 \\
\hline Chee Cheong Fan, plain & 1 roll & 133 & 1.5 \\
\hline Porridge, peanut and pork & 1 bowl & 211 & 2 \\
\hline Roti prata, with onion & 1 piece & 304 & 5 \\
\hline Nasi lemak & 1 packet & 494 & 1 \\
\hline Chwee Kway & 1 small & 56 & 3 \\
\hline Lontong & 1 plate & 466 & 4 \\
\hline Lor Mai Kai & 1 whole & 322 & 6 \\
\hline Beef Horfun & 1 plate & 697 & 5 \\
\hline Chicken rice & 1 plate & 607 & 4 \\
\hline Char Siew Rice & 1 plate & 605 & \\
\hline
\end{tabular}




\section{Current Research in Diabetes \& Obesity Journal}

\begin{tabular}{|c|c|c|c|}
\hline Nasi Briyani & 1 plate & 619 & 7 \\
\hline Penang fried kway teow & 1 plate & 510 & 4 \\
\hline Lor mee & 1 bowl & 383 & 5.5 \\
\hline Kway Chap & 1 portion & 703 & 4 \\
\hline Laksa lemak & 1 bowl & 591 & 4 \\
\hline Mee goring & 1 plate & 500 & 6 \\
\hline Mee siam & 1 plate & 694 & 5.5 \\
\hline Mee rebus & 1 plate & 571 & \\
\hline
\end{tabular}

Source: Asia Food Composition Table 2010, Health Promotion Board.

Table 5 shows some examples of foods with respective serving portion which contains one carbohydrate exchange $115 \mathrm{~g}$ carbohydrate) [8].

Table 6 shows is a list of common hawker foods with its calories, amount of carbohydrate and estimated carbohydrate exchange.

Table 6: Low, medium and high glycaemic index (G.I.) foods.

\begin{tabular}{|c|c|c|}
\hline Low G.I (Below 55) & Medium G.I (56 to 69) & High G.I (Above 70) \\
\hline Breads & Breads & White bread \\
\hline $100 \%$ stone ground whole wheat & Whole wheat & Kaiser roll \\
\hline Heavy mixed grain & Rye & Cereal \\
\hline Cereal & Pita & Corn flakes \\
\hline All Bran TM & Cereal & Rice Krispies TM \\
\hline Bran buds with psyllium & Grapenuts TM & Cheerios TM \\
\hline Oatmeal & Shredded wheat TM & Grains \\
\hline Oat bran & Quick oats & Short grain rice \\
\hline Grains & & Grains \\
\hline Heavy mixed grain & Whole wheat & Other \\
\hline Pumpernickel & Rye & Baked potato \\
\hline Other & Pita & French fries \\
\hline Sweet potato & Other & Rice cakes \\
\hline Yam & Potato, white & Soda crackers \\
\hline Legumes & Sweet corn & Pop corn \\
\hline
\end{tabular}

Source: Adopted from International Table of Glycemic Index and Glycemic Load values. Am J Clin Nutr. 2002;76: 5-76

The following example illustrates the calculation of total carbohydrate daily allowance (assuming 50\% of total calories) and the distribution of carbohydrate exchanges based on 1800 kcal requirement:

Total carbohydrate allowance per day $=50 \% \times 1800 \mathrm{kcal}=$ $900 \mathrm{kcal}$ divided by $4 \mathrm{kcal}=225 \mathrm{~g}$

Total carbohydrate exchange per day $=225 \mathrm{~g}$ divided by $15 \mathrm{~g}$ carbohydrate $=15$

Distribution of carbohydrate exchanges per day based on $50 \%$ of $1800 \mathrm{kcal}$ :
Mealtime Breakfast Snack Lunch Snack

Dinner Snack Total

$\begin{array}{llllll}* \text { CHO Ex. } & 4 & 1 & 4 & 1 & 4\end{array}$
15

*CHO Ex. - Carbohydrate exchange

Glycaemic index (G.I) and glycaemic load (G.L) the glycaemic index (G.I)

The Glycaemic Index (G.I) is a measure of the effects of carbohydrate on blood glucose levels. The G.I of a food is defined 


\section{Current Research in Diabetes \& Obesity Journal}

by the area under the 2-hour blood glucose response curve (AUC) following the ingestion of a fixed portion of carbohydrate (usually 50g). Then, the AUC of the particular test food is divided by the AUC of the standard reference food (either white bread or glucose) with the same amount of $50 \mathrm{~g}$ carbohydrate and multiplied by 100 . The average G.I value of a test food is calculated from data collected in 10 human subjects and the result gives a relative ranking for each test food [9]. Various studies have shown that low G.I foods produce small fluctuations in blood glucose and insulin levels, and hence lower glycaemic response which are beneficial for people with diabetes to improve their glycaemic control after ingestion of low G.I foods. The following are some benefits of low G.I foods [10] (Figure 2):

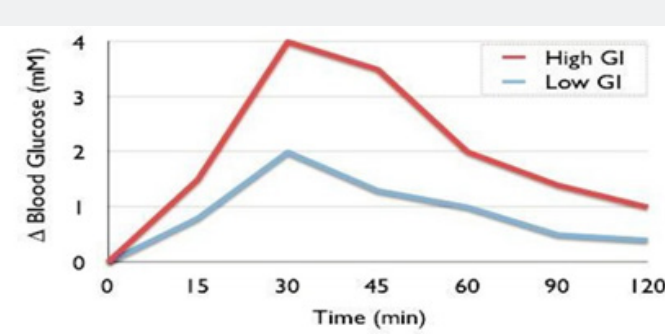

Figure 2: Blood glucose changes in response to high and low G.I. food

a) Help people to lose and control weight.

b) Increase the body's sensitivity to insulin.

c) Improve diabetes control by slowing down the absorption rate of blood glucose.

d) Reduce the risk of heart disease.

e) Reduce blood cholesterol level.

f) Help to manage symptoms of polycystic ovary syndrome

g) (PCOS).

h) Reduce hunger and keep you fuller for a longer period.

i) Prolong physical endurance.

Table 7: Sweeteners.

\begin{tabular}{|c|c|c|}
\hline $\begin{array}{c}\text { Nutritive } \\
\text { (4kcal/g) }\end{array}$ & $\begin{array}{c}\text { Low Calories } \\
\text { (2kcal/g) }\end{array}$ & Artificial Sweeteners \\
\hline Glucose & Sugar alcohols: & Saccharin (Sweet n Low ${ }^{\circledR}$ ) \\
\hline Dextrose & Mannitol & Aspartame (Equal ${ }^{\circledR}$ ) \\
\hline Maltose & Sorbitol & Acesulfame K (Sunette $\AA$ ) \\
\hline Sucrose & Xylitol & Sucralose (Splenda $\AA$ ) \\
\hline Fructose & Isomalt & Neotame \\
\hline Lactose & Maltitol & \\
\hline
\end{tabular}

The classifications of G.I value of certain foods are divided into three ranges as shown in Table 7 [11]: High G.I - Above 70; Medium G.I - 56 to 69; Low G.I - Below 55: However, various factors can affect the G.I value of a particular food as well such as: a) Form and structure of carbohydrate.

b) Texture of foods - size, ripeness, softness, viscosity.

c) Food processing-duration of process, temperature, pressure.

d) Nutrient content of the food - protein, fat, fibre.

e) Ingestion of a mixed diet versus single food component.

f) Species of foods.

Hence, low G.I foods should be used as a complementary therapy as part of healthy eating for people with diabetes to improve their glycaemic control.

The Glycaemic Load (G.L) is defined as a function of a food's glycaemic index (G.I) and its total available carbohydrate content. Therefore, G.L = G.I x Total carbohydrate $(\mathrm{g})$. Example using apple: The G.I of apple $=0.38$ and its carbohydrate content $=15 \mathrm{~g}$, therefore the G.L of one apple $=0.38 \times 15=6$; whereas G.L of two apples $=0.38 \times 6 \times 2=12$. The G.L of a meal can be lowered by: (i) choosing a lower G.I foods, (ii) reduce carbohydrate amount or; (iii) both ways.

However, various factors can affect the G.I value of a particular food as well such as:

i. Form and structure of carbohydrate.

ii. Texture of foods - size, ripeness, softness, viscosity.

iii. Food processing-duration of process, temperature, pressure.

iv. Nutrient content of the food - protein, fat, fibre.

v. Ingestion of a mixed diet versus single food component.

vi. Species of foods.

Hence, low G.I foods should be used as a complementary therapy as part of healthy eating for people with diabetes to improve their glycaemic control. The Glycaemic Load (G.L) is defined as a function of a food's glycaemic index (G.I) and its total available carbohydrate content. Therefore, G.L = G.I x Total carbohydrate (g). Example using apple: The G.I of apple $=0.38$ and its carbohydrate content $=15 \mathrm{~g}$, therefore the G.L of one apple $=0.38 \times 15=6$; whereas G.L of two apples $=0.38 \times 6 \times 2=$ 12. The G.L of a meal can be lowered by: (i) choosing a lower G.I foods, (ii) reduce carbohydrate amount or; (iii) both ways.

\section{Sweeteners}

Generally, there are three categories of sweeteners as shown in Table 8. Artificial sweeteners are sugar substitutes for people with diabetes who require sweetness for their beverages, desserts and pastries. At present, only 5 categories of artificial sweeteners are approved by United States Food and Drug Administration (USFDA) [12] which are safe for human consumption in moderation. However, there is no evidence to show that consumption or usage of artificial sweeteners in long term will lead to weight loss or improved glycaemic control for people with diabetes 


\section{Current Research in Diabetes \& Obesity Journal}

Table 8: Summary of recommendations for respective nutrients in chronic renal failure management

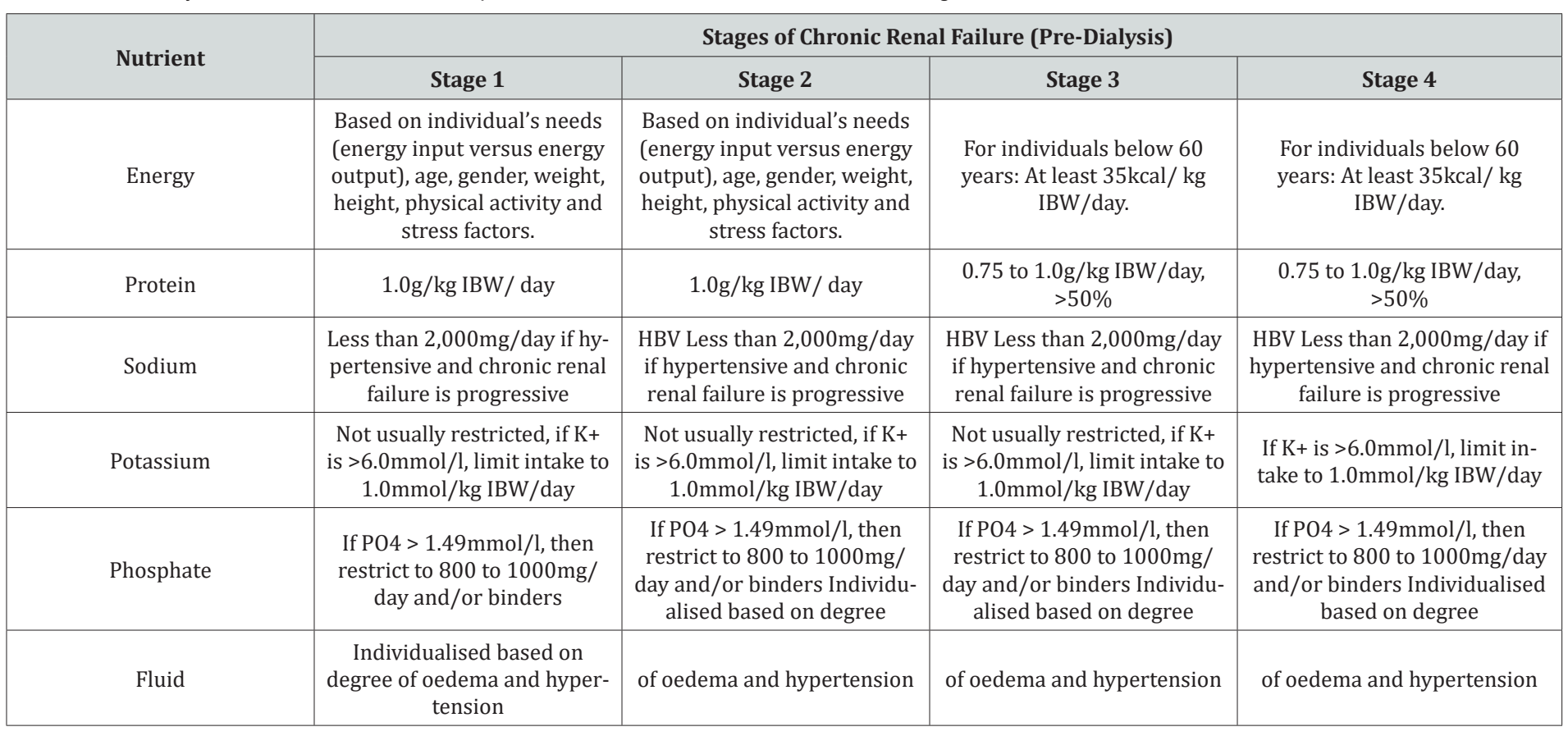

Summary of recommendations for respective nutrients in chronic renal failure management

\section{Common food myths for people with diabetes}

Myth \#1: People with diabetes should consume little amount of starchy foods such as rice, noodles, bread as these foods raise blood sugar level.

Fact \#1: Starchy foods such as rice, noodles and bread are the main source of carbohydrate which is used as the first fuel for the body. There is no evidence to show that people with diabetes should consume little amount of these starchy foods to improve blood sugar control. By doing so, this will tend to predispose the risk of low blood sugar level especially for those who are on insulin regimen. Indeed, they should be conscious with the amount of starchy foods (total carbohydrate) intake for each meal. The recommended intake of starchy foods is 5 to 7 servings daily [13].

Myth \#2: People with diabetes should avoid eating fruits with sweet taste.

Fact \#2: Fruits are rich in fibre, vitamins, minerals and antioxidants which are beneficial to health and prevent the risk of cardiovascular disease. People with diabetes should consume variety of fruits but in moderation; regardless sweet or sour taste because all fruits contain fructose (fruit sugar). The recommended intake of fruits is 2 servings daily and a serving at a time for people with diabetes. A serving of fruit can also be a healthy snack option to replace unhealthy options such as potato chips, ice cream or chocolate which are high fat and sugar content [14].
Myth \#3: People with diabetes should only consume special "diabetic foods".

Fact \#3: "Diabetic foods" or foods which are "suitable for diabetics" tend to be lower in carbohydrate content and replaced with higher fat content which in turn it does not make a significant difference in terms of calories content compared to the conventional food products. Therefore, "diabetic" foods can only be an option but not a necessity for people with diabetes. People with diabetes need not to rely only on "diabetic foods" to improve their blood sugar control [15].

Myth \#4: People with diabetes should consume a different diet from the rest of family members.

Fact \#4: There is no special diet or so called "diabetic" diet for people with diabetes. Current scientific evidence shows that people with diabetes should eat a similar diet as their family members provided all having a healthy dietary pattern which is low in fat especially low in saturated fats, low in salt, low in sugar, and rich in fibre [16].

Myth \#5: People with diabetes should consume a high protein diet to control blood sugar level.

Fact \#5: People with diabetes who consume a high protein diet especially from animal source such as meat, fish and poultry may end up having a higher amount of total calories intake because animal protein are naturally higher in fat content and due to the usual high fat cooking method for meat dish [1730]. This may lead to further weight gain along with increased insulin resistance which result in poorly controlled diabetes. Hence, people with diabetes need not to consume a high protein 


\section{Current Research in Diabetes \& Obesity Journal}

diet. The recommended intake of protein foods per day is 2 to 3 servings (Appendix \& Table 8) [31-50].

Moving forward, preventive nephrology [51] which aims for good diabetes control with $\mathrm{HbA} 1 \mathrm{c}<7.0 \%$, good blood pressure control $<130 / 80 \mathrm{mmHg}$, good lipids control as well as early detection of chronic diseases through ongoing health screening are important strategies in retarding progression of kidney damage and preserve remaining kidney function.

\section{Conclusions}

It is known that similar nutrition recommendations are useful to improve different chronic disease conditions, in which the healthy diet pyramid way of eating remains the fundamental way of healthy eating which emphasizes on variety, balanced and moderation; together with lots of fruits, vegetables, whole grains intake as part of daily diet. In order to achieve the target goals as established by medical nutrition therapy guidelines for each chronic disease, it requires individuals to make lifelong modifications by adopting a healthy lifestyle through regular exercise and healthy eating practice at any stage of diseases, with or without medication prescription.

\section{References}

1. World Health Assembly Resolution (2007) WHA Global strategy on diet, physical activity and health. Geneva, World Health Organization 57: 17 .

2. American Dietetics Association www.eatright.org-Definition of Medical Nutrition Therapy.

3. (1995) Position of the ADA: Cost effectiveness of Medical Nutrition Therapy. Journal of American Dietetics Association (JADA). 95: 88-91.

4. Part 2-Diabetes Mellitus, National Health Survey (2010) Epidemiology and Disease Division, Ministry of Health, Singapore.

5. (2006) MOH Clinical Practice Guidelines for Diabetes Mellitus, Singapore.

6. Bantle JP, Wylie-Rosett J, Albright AL, Apovian CM, Clark NG, et al. (2008) Nutrition Recommendations and Interventions for Diabetes, A Position Statement of the American Diabetes Association. Diabetes Care 31: S1-18.

7. ABC's of Healthy Eating Booklet, Health Promotion Board, Singapore.

8. Jenkins DJ, Wolever TM, Taylor RH, Barker H, Fielden H, et al. (1981) Glycaemic Index of Foods: a physiological basis for carbohydrate exchange. A J Clin Nutr 34: 362-366.

9. www.glycemicindex.com

10. (2002) International Table of Glycaemic Index and Glycaemic Load values. Am J Clin Nutr 76: 5-76.

11. Artificial sweeteners: No calories, Sweet.

12. (2004) Part 3- Hypertension, National Health Survey 2004, Epidemiology and Disease Division, Ministry of Health, Singapore.

13. (2005) MOH Clinical Practice Guidelines for Hypertension, Singapore.

14. Appel LJ (2006) Dietary Approaches to Prevent and Stop Hypertension. A Scientific Statement from American Heart Association. Hypertension 47(2): 296-308.
15. Sacks FM, Svetkey LP, Vollmer WM, Appel LJ, Bray GA, et al. (2001) Effects on Blood Pressure of Reduced Dietary Sodium and The Dietary Approaches to Stop Hypertension (DASH) Diet. DASH-Sodium Collaborative Research Group. The New England Journal of Medicine 344(1): 3-10.

16. Your Guide to lowering Your Blood Pressure with DASH.

17. (1998) US Department of Human and Health Services. National Institutes of Health, National Heart, Lung and Blood Institute.

18. (2004) Report of the National Nutrition Survey 2004, Research and Strategic Planning Division, Health Promotion Board, Singapore.

19. (2004) Part 3 - Cholesterol, National Health Survey 2004, Epidemiology and Disease Division, Ministry of Health, Singapore.

20. (2006) MOH Clinical Practice Guidelines for Hyper lipidaemia, Singapore.

21. (2001) Expert Panel on Detection, Evaluation and Treatment of High Blood Cholesterol in Adults. Executive summary of the third report of the National Cholesterol Education Program (NCEP) Expert Panel on Detection, Evaluation, and Treatment of High Blood Cholesterol in Adults (Adult Treatment Panel III). JAMA 285: 2486-2497.

22. (2003) Evidence Based Best Practice Guidelines - The Assessment and Management of Cardiovascular Risk, New Zealand Guidelines Group.

23. Mensink RP, Katan MB (1990) Effect of Dietary Trans Fatty Acids on High Density and Low-Density Lipoprotein Levels in Healthy Subjects. N Eng J Med 323: 439-445.

24. (2003) Diet, Nutrition and the Prevention of Chronic Diseases, WHO Technical Report Series 916. Report of a Joint WHO/FAO Expert Consultation. World Health Organisation Geneva, Switzerland.

25. (2003) Major food sources of trans fat for American adults, United States Food and Drug Administration's economic analysis for the final trans fatty acids labeling rule, trans fatty acids in nutrition labeling, Nutrient content claims and Health claims.

26. (2003) Questions and Answers about Trans Fat Nutrition Labeling. CFSAN Office of Nutritional Products, Labeling and Dietary Supplements.

27. Nutrition- Trans Fat, HPB Online. Health Promotion Board, Singapore.

28. VH Linda (1997) Fibre, Lipids and Coronary Heart Disease. A Statement for Healthcare Professionals from the Nutrition Committee, American Heart Association. Circulation 95(12): 2701-2704.

29. Olson BH, Anderson SM, Becker MP, Anderson JW, Hunninghake DB (1997) Psyllium-Enriched Cereals Lower Blood Total Cholesterol and LDL Cholesterol, but Not HDL Cholesterol, in Hypercholesterolemic Adults: Results of a Meta-Analysis. J Nutr 127: 1973-1980.

30. Brown L, Rosner B, Willett WW, Sacks FM (1999) Cholesterol-lowering effects of dietary fiber: a meta-analysis. Am J Clin Nutr 69:(1) 30-42.

31. Davy BM, Davy KP, Ho RC, Beske SD, Davrath LR, et al. (2002) High fiber oat cereal compared with wheat cereal consumption favorably alters LDL-cholesterol subclass and particle numbers in middle-aged and older men. Am J Clin Nutr 76(2): 351-358.

32. Jenkins DJ, Kendall CW, Vuksan V, Vidgen E, Parker T, et al. (2002) Soluble fiber intake at a dose approved by the US Food and Drug Administration for a claim of Health Benefits: serum lipid risk factors for a cardiovascular disease assessed in a randomized controlled crossover trial. Am J Clin Nutr 75(5): 834-839.

33. Ellegård LH, Andersson SW, Normén AL (2007) Andersson HA Dietary Plant Sterols and Cholesterol Metabolism. Nutr Rev, 65: 39-45.

34. (2007) Health Module, Nutrition Reviews 65(1). 


\section{Current Research in Diabetes \& Obesity Journal}

35. HFJ Hendriks, Weststrate JA, van Vliet T, Meijer GW (1999) Spreads enriched with three different levels of vegetable oil sterols and the degree of cholesterol lowering in normocholesterolemic and mildly hypercholesterolemia subjects. Eur J Clin Nutr 53: 319-327.

36. MB Katan (2003) Efficacy and Safety of plant stanols and sterols in the management of blood cholesterol level. Mayo Clin Proc 78 (8): 965 978.

37. TA Miettinen (1995) Reduction of serum cholesterol with sitostanolester margarine in a mildly hyper cholesterol emic population. $\mathrm{N}$ Eng J Med 333: 1308-1312.

38. S Anderson, Skinner J, Ellegård L, Welch AA, Bingham S (2004) Intake of plant sterols is inversely related to serum concentration in men and women in the EPIC Norfolk population: a cross-sectional study. Eur J Clin Nutr 58(10): 1378-1385.

39. www.goutdiettips.com/gout-symptoms-four-stages-of-gout

40. www.saclinpath.co.za/documents/uric.doc

41. Rodnan GP (1980) The pathogenesis of aldermanic gout: procatarctic role of fluctuations in serum urate concentration in gouty arthritis provoked by feast and alcohol. Arthritis Rheum 23: 737.

42. BT Emmerson (1996) The management of Gout. N Eng J Med 334: 445 451
43. www.mdmazz.com/goutdiet.pdf

44. Pennington JA (1998) Bowes \& Church's food values of portions commonly used $\left(17^{\text {th }}\right.$ edn) Philadelphia: Lippincott-Raven Publishers.

45. Mahan LK, Escott Stump S (2000) Krause's food, nutrition and diet therapy (10 ${ }^{\text {th }}$ edn.), Philadelphia: WB Saunders Company.

46. Choi (2004) Purine-rich foods, dairy, and protein intake and the risk of gout in men. N Eng J Med 350: 1093-1103.

47. (2002) National Kidney Foundation Kidney Disease Outcome Quality Initiative (K/DOQI) Advisory Board. K/DOQI Clinical Practice Guidelines for Chronic Kidney Disease: Evaluation, Classification and Stratification. American Journal of Kidney Diseases 39: s1-s246.

48. FJ Zeman. The Urinary System, Clinical Nutrition and Dietetics $\left(2^{\text {nd }}\right.$ edn). Mac Millan Publishing Company, New York, USA.

49. A Vathsala (2007) Twenty-five facts about Kidney Disease in Singapore: In remembrance of World Kidney Day. Ann Acad Med Singapore.36(3): 157-160.

50.(2005) Evidence Based Practice Guidelines for Nutritional Management of Chronic Kidney Disease. Australia and New Zealand Renal Guidelines Taskforce.

51. A Vathsala, HK Yap (2005) Annals Academy of Medicine 34(1).
Your next submission with Juniper Publishers will reach you the below assets

- Quality Editorial service

- Swift Peer Review

- Reprints availability

- E-prints Service

- Manuscript Podcast for convenient understanding

- Global attainment for your research

- Manuscript accessibility in different formats

( Pdf, E-pub, Full Text, Audio)

- Unceasing customer service

Track the below URL for one-step submission https://juniperpublishers.com/online-submission.php 